\author{
YUKIKO UCHIDA, VINAI NORASAKKUNKIT and SHINOBU \\ KITAYAMA
}

\title{
CULTURAL CONSTRUCTIONS OF HAPPINESS: THEORY AND EMPIRICAL EVIDENCE
}

\begin{abstract}
In a review of recent cross-cultural evidence on happiness and well-being, the authors identified substantial cultural variations in (1) cultural meanings of happiness, (2) motivations underlying happiness, and (3) predictors of happiness. Specifically, in North American cultural contexts, happiness tends to be defined in terms of personal achievement. Individuals engaging in these cultures are motivated to maximize the experience of positive affect. Moreover, happiness is best predicted by self-esteem. In contrast, in East Asian cultural contexts, happiness tends to be defined in terms of interpersonal connectedness. Individuals engaging in these cultures are motivated to maintain a balance between positive and negative affects. Moreover, happiness is best predicted by perceived embeddedness of the self in a social relationship. Directions for future research are discussed.
\end{abstract}

The present paper is concerned with cross-cultural variations and similarities of happiness and subjective well-being. In the contemporary literature, subjective well-being is typically defined as an overall cognitive appraisal of the quality of one's own life (see e.g., Diener, 2000 for a review). Happiness is an emotional concomitant to this overall judgment. Defined in this general way, happiness is likely to be universal and more or less equally valued across different cultures (e.g., Ryan et al., 1996; Ryff and Keyes, 1995). Indeed, people everywhere are likely to prefer the desirable over the undesirable and the pleasant over the unpleasant (Diener, Diener and Diener, 1995; Michalos, 1991; Veenhoven, 1991). However, it is also likely that exactly what constitutes the good and the valuable varies substantially across cultures (Diener and Suh, 2000; Kitayama and Markus, 2000). As a consequence, we may expect considerable cross-cultural variations in meanings of happiness (i.e., what might constitute happiness), motivations underlying happiness (i.e., what people might try to do to achieve 
happiness), and predictors of happiness (i.e., what factors might predict happiness).

\section{THEORY: CULTURE AND HAPPINESS}

\section{Cultural Perspective}

In psychology, emotions have often been seen as universal and biologically determined (Ekman, 1992). More recently, however, a number of culturally oriented psychologists have emphasized the critical role of public meanings (folk theories and commonsense) and practices (daily routines and scripts) in shaping emotions (Benson, 2000; Bruner, 1990, 1996; Kitayama, 2002; Markus and Kitayama, 1991a; Shweder and Sullivan, 1993). These meanings and practices constitute local "ways of life", which as a whole define a culture (Bruner, 1990).

These culturally oriented theorists have argued that emotions are not the direct outcome of physiological or neurological mechanisms. Rather, emotions are always situated and embedded in specific cultural contexts. Accordingly, they are fully saturated with cultural meanings (Kitayama et al., 2004). This analysis implies, for example, that what happiness means might vary considerably across cultures (Diener and Suh, 2000; Kitayama and Markus, 2000). Thus, people in different cultures might categorize quite different sorts of positive events and experiences as instances of happiness. Underlying this cross-culturally divergent construal and experience of emotion is a set of culturally shared ideas about personhood - namely, these about what is the self, what self one would hope to be, and what social relations one should have with other selves.

\section{Happiness in East and West}

Markus and Kitayama (1991a, 2004; Kitayama and Markus, 2000) have called ideas about personhood the cultural models or construals of self, and suggested that these models of self are implicated in all aspects of psychological processes evoked in social life including cognition, emotion, and motivation. Their analysis is informed by in-depth analyses of two broadly defined regions of the world, namely, European-American cultures and 
East Asian cultures. Although each cultural region is diverse by itself and, therefore, there is likely to be considerable within-regional variations, it remains to be the case that each of the two regions has historically shared substantial amount of pertinent ideas, practices, and social institutions.

Specifically, in European and North American cultures such as the American middleclass culture there is a strong belief in the independence and autonomy of the self. The self is believed to be the center of thought, action, and motivation. It is bounded and separate from other such selves. Social relations are quite important; yet, they are constructed in accordance with the fundamental assumption about the independence of each self. Specifically, they are based on choice of each self to enter such relations. These ideas are widely distributed in European-American cultural contexts and, in fact, they are quite instrumental in organizing daily practices, routine discourses and narratives, and institutions of these contexts.

Given the independent model, the most central aspect of the self is a set of internal attributes. Individuals are therefore highly motivated to find and affirm the positivity of these attributes. This implies that happiness in European-American cultures is likely to hinge critically on the affirmation of positive attributes of the self. Moreover, happiness itself is often construed as one of those internal attributes that are to be pursued and attained via personal striving. In other words, happiness is likely to be constructed as personal achievement.

In contrast, in East Asian cultures, there is a contrasting assumption about the connectedness and interdependence of self with others. The self-in-relationship-with-others is believed to be the locus of thought, action, and motivation. The symbolic boundary between the self and other such selves is blurred and constantly negotiated through social interaction. Personal selves are quite important; yet, they are constructed in accordance with the fundamental assumption about the interdependence of the selves involved. For example, in East Asian cultural contexts, strong personal egos appear to emerge through identification with significant others or rebellion against them, both of which involve an immersion into close interpersonal relations. Ideas about the interdependent nature of human being are quite widespread in 
East Asian cultures. Moreover, these ideas are often underlying the practices, daily routines, discourses and social institutions that, as a whole, define the social realities of these cultural contexts.

Individuals in East Asian cultural contexts are highly motivated to adjust and fit themselves to the pertinent social relations. Commitments to social roles, social obligations, and readiness to respond to social expectations are all manifestations of this socially oriented motivation for realizing an interdependent self (Morling et al., 2002; Weisz et al., 1984). This implies that happiness in East Asian cultures is likely to depend crucially on the realization of positive social relationship of which the self is part. Personal happiness often damages social relationship. For example, emphasizing a success of the self may lead to jealousy and envy by others. The personal form of happiness is therefore often perceived to be tainted and incomplete, and as a consequence, there is no strong desire to pursue personal happiness at the expense of social harmony. Instead, happiness is seen as an inter-subjective state that is grounded in mutual sympathy, compassion, and support. In short, happiness is constructed as realization of social harmony (Kitayama and Markus, 2000).

The foregoing analysis offers some important implications regarding the nature of happiness in different cultural contexts. Specifically, recent evidence suggests that there are systematic cross-cultural differences in three domains, namely: (1) cultural meanings of happiness, (2) motivations underlying happiness, and (3) correlates of happiness. We now turn to a review of this empirical evidence.

\section{EMPIRICAL EVIDENCE}

\section{Cultural Meanings of Happiness}

Happiness may be defined as a positive emotional state that is most general and, thus, not restricted to any specific circumstances or events (Kitayama, Markus and Matsumoto, 1995, 2000). Defined in this broad term, happiness is likely to be universal. Although happiness is experienced as unqualified, this experience itself is embedded in specific socio-cultural contexts and circumstances and, therefore, is likely to be highly contingent on these contexts and circumstances. In accordance with the 
foregoing analysis on culture and self, we propose that happiness is encompassed in a rich associative network that is largely culture dependent and, thus, cross-culturally variable.

Specifically, in North America happiness may most typically be construed as a state contingent on both personal achievement and positivity of the personal self. Negative features of the self and negative feelings are thus perceived to be a hindrance against positivity and happiness. In contrast, in East Asia happiness is likely to be construed as a state that is contingent on social harmony and, thus, on a balance among different selves in a relationship.

These cultural views of happiness are grounded in historically nurtured ideologies and religious ideas. It is easy, for example, to identify some close affinities between the European-American view of happiness as personal achievement and the Protestant worldview (Kitayama and Markus, 1999). According to this worldview, individuals are predestined to be either "select" or "doomed" (Weber, 1930). The belief in predestination, in turn, generates a strong desire for affirming the self as worthy, competent, true to the intent of the God and, thus, as "select". Affirmation of personal worthiness ("me" as smart, friendly, kind, etc.) may therefore serve as a quite effective buffer against anxiety of a negative prospect of the self as "doomed" (e.g., "me" as dumb, stupid, and ugly). Along with other ideas such as person as commodity, social relations as market, and personal choice as a God-given right, the Protestant view of personhood has historically encouraged the construal of happiness as personal achievement and as a state that is contingent on the affirmation of personal self.

Likewise, there are some close links between the East Asian view of happiness as realization of social harmony and certain Asian strands of ideas as revealed in Confucianism, Taoism, and Buddhism. All these ideologies and worldviews emphasize a holistic world order where everything is assumed to be connected with everything else. In particular, what is good in personal domains are often assumed to lead to certain social problems (Kitayama and Markus, 1999; Suh, 2002). There is an explicit recognition, for example, that a personal success may entail a negative consequence by inviting someone's jealousy. Likewise, 
what is bad personally is often seen as a cause for certain positive social consequences. A personal failure, for example, may be an opportunity for receiving social support and compassion from others. These dialectic views of the world in general and of happiness in particular, are part and parcel of the happiness as that results from social harmony and social balance.

In the recent years, some researchers have empirically investigated the culturally divergent meanings of happiness. These studies suggest that whereas in European-American cultures positivity and negativity are often seen as contradictory, in East Asian cultures they are seen as complementary. For example, Ji et al. (2001) presented Chinese and American participants with graphs representing either a linear or nonlinear trend and asked them to indicate which graph might best represent the change of happiness in the life. Whereas Chinese respondents were likely to choose a nonlinear graph, Americans were likely to choose a linear graph.

A similar point has been made in recent studies that examine cross-culturally different associations between positive and negative emotions. Bagozzi et al. (1999) measured the intensity of pleasant and unpleasant emotions and found that whereas these two types of emotions were negatively correlated in the U.S., they were positively correlated in China and Korea. Hence, Americans experience positive and negative emotions as bipolar opposites, but East Asians appear to experience these emotions in a more simultaneous fashion. Kitayama et al. (2000) found a similar pattern with a different measure. These researchers asked American and Japanese participants to report how frequently they experience some different types of positive and negative emotions. Some emotions were interpersonally engaging (e.g., friendly feelings, ashamed), but some others were interpersonally disengaging (e.g., pride, angry). Still some others were general ones that are much less specific in their antecedents and consequences (e.g., calm, elated, happy). The correlations between the positive and negative emotions are shown in Figure 1. For the most part, they are highly negative in the U.S., but in Japan, most of them are positive. On the basis of this evidence, Kitayama and colleagues speculate that people in independent cultures (e.g., Americans) may be motivated to maximize pleasant emotions and minimize 


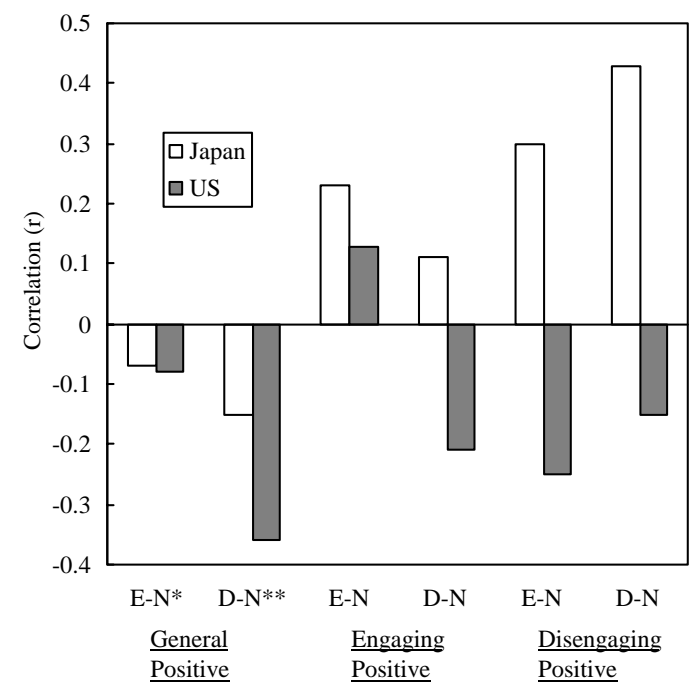

Figure 1. Correlations between positive and negative emotions in Japan and the United States. (Figure 2 in Kitayama et al., 2000)* Engaging negative, ** Disengaging negative.

unpleasant emotions, but people in interdependent cultures (e.g., Japanese) may be motivated to maintain a balance between positivity and negativity. We now turn to a discussion on cultural differences in motivation involved in happiness.

\section{Motivations Underlying Happiness}

If the meaning of happiness is cross-culturally divergent, it is likely that motivations implicated in happiness are also likely to vary. Specifically, in cultures where happiness is construed to be a personal achievement, individuals are likely to be highly motivated to affirm positive personal attributes as an integral part of their pursuit of happiness. In contrast, in cultures where happiness is construed to be a realization of social harmony, there will be little or no strong desire for achieving personal happiness insofar as there is an explicit recognition that doing so is likely to hinder the realization of social harmony and thus of a more socially grounded form of happiness (Diener, Suh, Smith and Shao, 1995).

Quite consistent with this analysis, a growing body of literature on self-serving motivations across cultures has demonstrated that Americans are much more likely than Asians to seek and confirm 
positive internal attributes of the self. The cross-cultural difference in self-serving or self-enhancing motivations has been demonstrated in causal attribution of success and failure (Kitayama, Takagi and Matsumoto, 1995), self-referent judgments (Heine and Lehman, 1995; Markus and Kitayama, 1991b), judgment about ingroup (Conner-Snibbe et al., 2003), and readiness to accept either positive or negative feedback about the self (Heine et al., 2001; Kitayama et al., 1997). Summarizing this literature, Hiene and colleagues (1999) note that the tendency toward positivity of the self is constantly reinforced and required to be a respectable cultural member in North America, but probably not in Japan.

Evidence also suggests that Americans are more likely than Asians to actively seek to achieve personal happiness. For example, Kitayama and colleagues (2000) found that Americans are far more likely than Japanese to reportedly experience positive emotions. This evidence is consistent with evidence from a largescale international survey that shows that the average levels of subjective well-being are much higher in individualist cultures than in collectivist cultures (Diener, Diener and Diener, 1995). More recently, Oishi (2002) suggests that the cross-cultural difference observed here is unlikely to be due to any difference in actual emotional experience. Instead it seems to be due largely to a motivated tendency of Americans to remember positive emotional experience (see also Diener et al., 2002).

Instead of pursuing personal happiness, Asians may be strongly motivated to seek more communal or intersubjective forms of happiness. In a recent cross-cultural survey (Morling et al., 2003), Japanese pregnant women were more likely than their American counterparts to seek and rely on advice, opinions and judgments of their close others such as their partner, parents and doctors. Moreover, evidence suggests that individuals with Asian cultural heritage are more prone than those with European American heritage to use expectations by close others in organizing their own behaviors (Iyenger and Lepper, 1999). It is likely, then, that Asians are more likely than European-Americans to be concerned with approvals by close others (Kitayama et al., in press). It may then be predicted that care and support by close others are likely to be directly implicated in the happiness of many Asians. 


\section{Predictors of Happiness}

Depending on the cultural meanings of happiness and the corresponding motivations underlying happiness, there should be quite divergent sets of factors that predict happiness in different cultures. Specifically, our analysis suggests that whereas in European American cultures factors that are related to personal achievement should be the primary predictor of happiness, in East Asian cultures those that are linked to realization of social harmony should serve as much more reliable predictors of happiness.

The factors that are almost always correlated with happiness in North American cultures are personal accomplishment (e.g., Emmons, 1986, 1991) and self-esteem (Campbell, 1981; Diener and Diner, 1995; Diener et al., 1985). Taylor and Brown (1988) argue that perception of one's positivity, even when it is illusory, can contribute to mental health.

In other cultural contexts, especially in East Asian contexts, however, the significance of self-esteem is questionable. Diener and Diener (1995) investigated 31 countries and found that selfesteem is more strongly correlated with subjective well-being in individualistic (e.g., European-American) cultures than in collectivistic (e.g., East Asian) cultures. We have suggested that in these latter cultures, happiness is grounded in social harmony and connectedness. In these cultures, then, factors that are related to social harmony should more reliably predict happiness (Endo, 1995; Kitayama and Markus, 2000; Suh et al., 1998). Consistent with this reasoning, Suh and his colleagues (1998) have shown that positive affect enhances the feelings of happiness in North America, but it is other, more social factors (such as adapting to social norms and fulfilling relational obligations), that increase happiness in East Asia. These social factors contribute to social harmony.

More recent studies have simultaneously examined both selfesteem and social harmony in predicting happiness. In one such study, Oishi and Diener (2001) asked European-American and Asian-American participants to list five important goals they hope to accomplish in the next one month. The participants then judged the extent to which each goal was related to independence (i.e., an attainment of one's own fun or enjoyment). One month later, participants evaluated their satisfaction with life during the 
past one month. They also judged the extent to which each goal had been achieved. As can be seen in Figure 2, for the EuropeanAmerican sample, happiness increased as more independent goals were achieved. In contrast, for the Asian sample, happiness increased instead as a function of the achievement of goals that were rated to be less independent (and therefore probably more interdependent, e.g., bringing happiness to parents).

A similar point has been made by Kitayama and his colleagues (2000). These researchers asked American and Japanese participants to report how frequently they experience interpersonally engaging positive emotions - emotions resulting from social harmony (e.g., friendly feelings), interpersonally disengaging positive emotions - emotions resulting from personal achievement (e.g., pride, self-esteem), and general positive emotions (e.g., happy, calm, elated, relaxed). The correlations among these emotions, shown in Figure 3, indicate that in the U.S., the reported frequency of experiencing general positive emotions (e.g., happy) is more closely correlated with the reported frequency of experiencing disengaging positive emotions (e.g., pride) than with the frequency of experiencing engaging positive emotions (e.g., friendly feelings). In contrast, in Japan, the frequency of experiencing general positive emotions was more strongly correlated with the frequency of experiencing engaging positive emotions than with the frequency of experiencing disengaging positive emotions. This data pattern suggests that whereas in European-

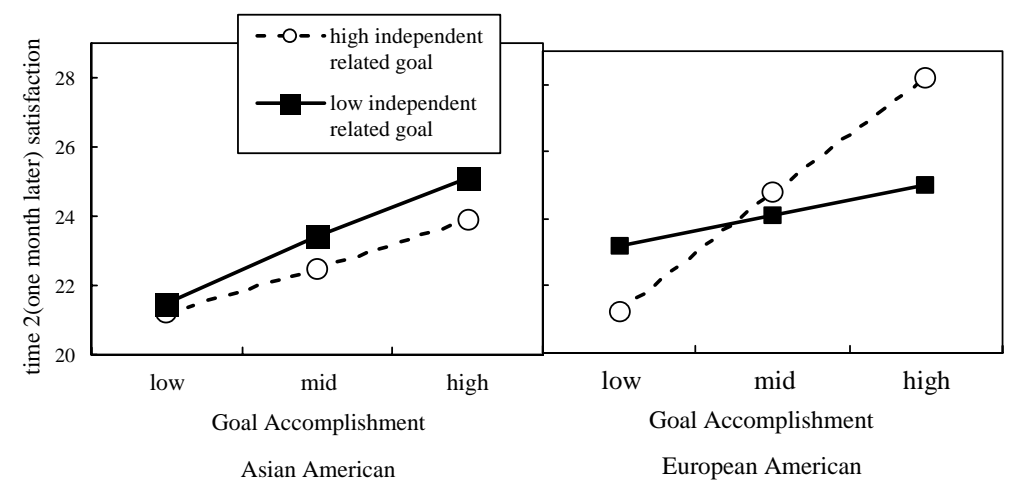

Figure 2. Adjusted monthly satisfaction as a function of goal attainment for Asian Americans and European Americans with high and low independent goal pursuit. (Modified version of Figure 1 in Oishi and Diener, 2001.) 


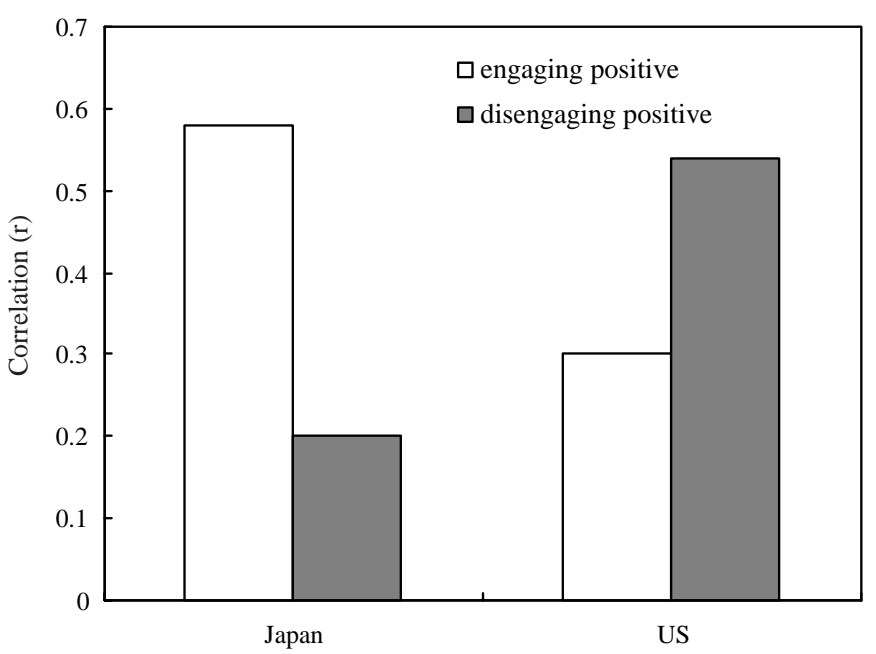

Figure 3. Predicting general positive emotions as a function of engaging emotions (e.g., friendly feelings) and disengaging emotions (e.g., self-esteem) in the US and Japan. (The data reported in Kitayama et al., 2000.)

American cultures personal achievement is a primary antecedent of happiness, in Asian cultures, social harmony may be more important.

Some other studies have made the same point with trait measures. In one of the earlier studies of this type, Kwan et al. (1997) examined the relative importance of self-esteem and relationship harmony to attain life satisfaction in Hong Kong and the U.S. These researchers found that in the U.S., self-esteem was the only predictor of life satisfaction, but in Hong Kong, relationship harmony was equally important in predicting life satisfaction. More recently, Uchida et al. (2001) examined both self-esteem and perceived emotional support from close others as potential predictors of happiness. These researchers found that in two different Asian cultures (Japan and the Philippines) both self-esteem and perceived emotional support were equally predictive of happiness. As predicted, however, in the U.S. happiness was reliably predicted only by self-esteem (see Figure 4). It is likely that in independent cultures emotional supports such as encouragement, compassion, and sympathy often carry ambivalent meanings: They may signify both the worthiness of the self and the weakness of the self. As a consequence, emotional supports may contribute to happiness only to 


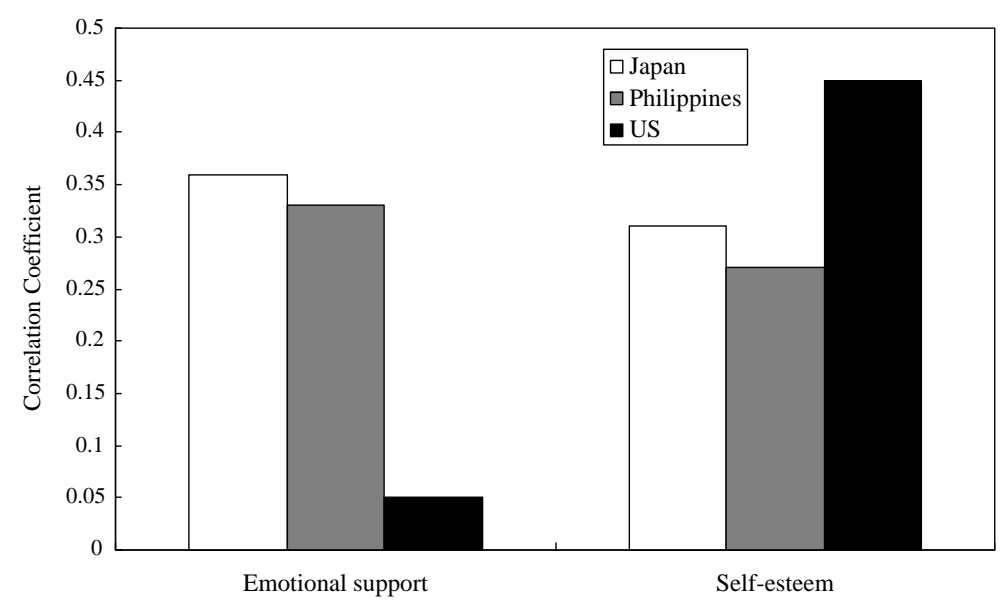

Figure 4. Predictors of happiness in Japan, the Philippines, and the United States. (Modified version of Figure 1 in Uchida et al., 2001.)

the extent that they do not threaten self-esteem. Quite consistent with this line of analysis, Uchida and colleagues (2001) found that in the American sample, the effect of perceived emotional support on happiness was entirely mediated by self-esteem.

\section{CONCLUSIONS}

In this paper, we have shown some substantial cross-cultural variations in happiness. Overall, in European-American cultures happiness tends to be defined and experienced as personal achievement, in East Asian cultures it tends to be defined and experienced as a realization of social harmony. Three lines of research (i.e., cultural meanings of happiness, happiness-related motivations, and predictors of happiness) have converged to provide empirical evidence for this analysis. Yet, there are some significant issues that must be addressed in future work.

To begin with, Norasakkunkit and Kalick (2002) have argued that there is an inherent bias in the concept of well-being that is tacitly embedded in conventionally used measures of emotional distress in favor of independent goals and their social-cognitive constituents (i.e., self-enhancing tendencies). Given this standard, those with interdependent selves (i.e., Asians) may be judged to be less healthy and emotionally more distressed than those with 
independent selves (European-Americans). Future work in this area may benefit from an effort to develop culture-specific measures of happiness and well-being.

Moreover, it is important to extend the analysis of happiness to mental illness. Although it is likely that factors related to happiness and subjective well-being are also related to other aspects of health (i.e., physical health) and illness in general, this point has yet to be examined in cross-cultural contexts. It is well known that mental illness can take quite divergent forms across cultures (e.g., Al-Issa and Oudji, 1998; Kirmayer, 1991; Kleinknecht et al., 1997; Kleinman and Good, 1985; Marsella et al., 1996). Correspondingly, effective strategies of health-related interventions may also be different. Thus, future work may seek to find the specific forms of interventions that are culturally appropriate and, thus, effective.

In conclusion, empirical work over the last decade has provided initial evidence for the hypothesis that happiness and wellbeing are significantly grounded in socio-cultural modes of being a person and interacting with others. This by no means denies universal underpinnings of happiness and well-being. However, it does mean that any adequate understanding of seemingly universal factors can never be complete without taking into account culture-dependent ways in which such factors are realized and allowed to shape happiness and well-being.

\section{ACKNOWLEDGEMENTS}

Yukiko Uchida, Research Fellow of the Japan Society for the Promotion of Science, was supported by Grant-in-Aid for JSPS Fellows. Also, this research was supported by the 21st Century COE Program (D-2 to Kyoto University), MEXT, Japan and grants-in-aid from the Ministry of Science and Education, Japan.

\section{REFERENCES}

Al-Issa, I. and S. Oudji: 1998, 'Culture and anxiety disorders', in S. Kazarian and D. Evans (eds), Cultural Clinical Psychology: Theory, Research, and Practice (Oxford University Press, Oxford), pp. 127-151.

Bagozzi, R.P., N. Wong and Y. Yi: 1999, 'The role of culture and gender in the relationship between positive and negative affect', Cognition and Emotion 13, pp. 641-672. 
Benson, C.: 2000, The Cultural Psychology of Self: Place, Morality and Art in Human Worlds (Routledge, Philadelphia, PA).

Bruner, J.: 1990, Acts of Meaning (Harvard University Press, Cambridge, MA).

Bruner, J.: 1996, The Culture of Education (Harvard University Press, Cambridge, MA).

Campbell, A.: 1981, The Sense of Well-being in America (McGraw-Hill, New York).

Conner-Snibbe, A., S. Kitayama, H.R. Markus and T. Suzuki: (2003), 'They saw a game: A Japanese and American field study', Journal of Cross-Cultural Psychology 34, pp. 581-595.

Diener, E.: 2000, 'Subjective well-being: The science of happiness and a proposal for a national index', American Psychologist 55, pp. 34-43.

Diener, E. and M. Diener: 1995, 'Cross cultural correlates of life satisfaction and self-esteem', Journal of Personality and Social Psychology 68, pp. 653-663.

Diener, E., R.A. Emmons, R.J. Larsen and S. Griffin: 1985, 'The satisfaction with life scale', Journal of Personality Assessment 49, pp. 71-75.

Diener, E., M. Diener and C. Diener: 1995, 'Factors predicting the subjective well-being of nations', Journal of Personality and Social Psychology 69, pp. 851-864.

Diener, E., R.E. Lucas, S. Oishi and E.M. Suh: 2002, 'Looking up and looking down: Weighting good and bad information in life satisfaction judgement', Personality and Social Psychology Bulletin 28, pp. 437-445.

Diener, E. and E.M. Suh (eds): 2000, Cultural and Subjective Well-Being (The MIT Press, Cambridge, MA).

Diener, E., E.M. Suh, H. Smith and L. Shao: 1995, 'National differences in reported subjective well-being: Why do they occur?', Social Indicators Research 34, pp. 7-32.

Ekman, P.: 1992, 'An Argument for Basic Emotions', Cognition and Emotion 6, pp. 169-200.

Emmons, R.A.: 1986, 'Personal strivings: An approach to personality and subjective well-being', Journal of Personality and Social Psychology 51, pp. 1058-1068.

Emmons, R.A.: 1991, 'Personal strivings, daily life events, and psychological and physical well-being', Journal of Personality 59, pp. 453-472.

Endo, Y.: 1995, 'Argument of the self as an index of mental health', Japanese Journal of Social Psychology 11, pp. 134-144.

Heine, S.J., S. Kitayama and D.R. Lehman: 2001, 'Cultural differences in selfevaluation: Japanese readily accept negative self-relevant information', Journal of Cross-Cultural Psychology 32, pp. 434-443.

Heine, S.J. and D.R. Lehman: 1995, 'Cultural variation in unrealistic optimism: Does the West feel more vulnerable than the East?', Journal of Personality and Social Psychology 68, pp. 595-607.

Heine, S.J., D.R. Lehman, H.R. Markus and S. Kitayama: 1999, 'Is there a universal need for positive self-regard?', Psychological Review 106, pp. 766794. 
Iyengar, S.S. and M.R. Lepper: 1999, 'Rethinking the value of choice: A cultural perspective on intrinsic motivation', Journal of Personality and Social Psychology 76, pp. 349-366.

Ji, L., R.E. Nisbett and Y. Su: 2001, 'Culture, change, and prediction', Psychological Science 12, pp. 450-456.

Kirmayer, L.J.: 1991, 'The place of culture in psychiatric nosology: Taijin kyofusho and DSM-III-R', Journal of Nervous and Mental Disease 179, pp. 19-28.

Kitayama, S.: 2002, 'Culture and basic psychological processes - Toward a system view of culture: Comment on Oyserman et al. (2002)', Psychological Bulletin 128, pp. 89-96.

Kitayama, S., A. Conner-Snibbe, H.R. Markus and T. Suzuki: in press, 'Is there any free choice?', Self and Dissonance in two cultures, Psychological Science.

Kitayama, S. and H.R. Markus: 1999, 'Yin and yang of the Japanese self: The cultural psychology of personality coherence', in D. Cervone and Y. Shoda (eds), The Coherence of Personality: Social Cognitive Bases of Personality Consistency, Variability, and Organization (Guilford, New York), pp. 242302.

Kitayama, S. and H.R. Markus: 2000, 'The pursuit of happiness and the realization of sympathy: Cultural patterns of self, social relations, and wellbeing', in E. Diener and E.M. Suh (eds), Cultural and Subjective Well-Being (The MIT Press, Cambridge, MA), pp. 113-161.

Kitayama, S., H.R. Markus and M. Kurokawa: 2000, 'Culture, emotion, and well-being: Good feelings in Japan and the United States', Cognition and Emotion 14, pp. 93-124.

Kitayama, S., H.R. Markus and H. Matsumoto: 1995, 'Culture, self, and emotion: A cultural perspective on "self-conscious" emotions', in J.P. Tangney and K.W. Fischer (eds), Self-conscious Emotions: The Psychology of Shame, Guilt, Embarrassment, and Pride (Guilford Press, New York), pp. 439-464.

Kitayama, S., H.R. Markus, H. Matsumoto and V. Norasakkunkit: 1997, 'Individual and collective processes in the construction of the self: Selfenhancement in the United States and self-criticism in Japan', Journal of Personality and Social Psychology 72, pp. 1245-1267.

Kitayama, S., B. Mesquita and M. Karasawa: 2004, The emotional basis of independent and interdependent selves: Socially disengaging and Engaging emotions in the US and Japan. Unpublished manuscript, University of Michigan.

Kitayama, S., H. Takagi and H. Matsumoto: 1995, 'Cultural psychology of Japanese self: Causal attribution of success and failure', Japanese Psychological Review 38, pp. 247-280.

Kleinknecht, R.A., D.L. Dale, E.E. Kleinknecht and N. Hiruma: 1997, 'Cultural factors in social anxiety: A comparison of social phobia symptoms and Taijin Kyofusho', Journal of Anxiety Disorders 11, pp. 157-177. 
Kleinman, A. and B. Good (eds): 1985, Culture and Depression: Studies in the Anthropology and Cross-Cultural Psychiatry of Affect and Disorder (University of California Press, Los Angeles, CA).

Kwan, V.S.Y., M.H. Bond and T.M. Singelis: 1997, 'Pancultural explanations for life satisfaction: Adding relationship harmony to self-esteem', Journal of Personality and Social Psychology 73, pp. 1038-1051.

Markus, H.R. and S. Kitayama: 1991a, 'Culture and the self: Implications for cognition, emotion, and motivation', Psychological Review 98, pp. 224-253.

Markus, H.R. and S. Kitayama: 1991b, 'Cultural variation in the self-concept', in G.R. Goethals and J. Strauss (eds), Multidisciplinary Perspectives on The Self (Springer-Verlag, New York), pp. 18-48.

Markus, H.R. and S. Kitayama: 2004, 'Models of agency: Sociocultural diversity in the construction of action', In V. Murphy-Berman and J. J. Berman (eds), Nebraska Symposium on Motivation: Vol 49. Cross-Cultural Differences in Perspectives on the Self (University of Nebraska Press, Lincoln), pp. 1-57.

Marsella, A.J., M.J. Friedman, E.T. Gerrity and R.M. Scurfield (eds): 1996, Ethnocultural Aspects of Posttraumatic Stress Disorder: Issues, Research, and Clinical Applications (American Psychological Association, Washington, DC).

Michalos, A.C.: 1991, Global Report on Student Well-Being, Vol. 1-4. (Springer-Verlag, New York).

Morling, B., S. Kitayama and Y. Miyamoto: 2002, 'Cultural practices emphasize influence in the United States and adjustment in Japan', Personality and Social Psychology Bulletin 28, pp. 311-323.

Morling, B., S. Kitayama and Y. Miyamoto: 2003, 'American and Japanese women use different coping strategies during normal pregnancy', Personality and Social Psychology Bulletin 29, pp. 1533-1546.

Norasakkunkit, V. and S.M. Kalick: 2002, 'Culture, ethnicity, and emotional distress measures: The role of self-construal and self-enhancement', Journal of Cross-Cultural Psychology 33, pp. 56-70.

Oishi, S.: 2002, 'The experiencing and remembering of well-being: A crosscultural analysis', Personality and Social Psychology Bulletin 28, pp. 13981406.

Oishi, S. and E. Diener: 2001, 'Goals, culture, and subjective well-being', Personality and Social Psychology Bulletin 27, pp. 1674-1682.

Ryan, R.M., K.M. Sheldon, T. Kasser and E.L. Deci: 1996, 'All goals are not created equal: An organismic perspective on the nature of goals and their regulation', in P.M. Gollwitzer and J.A. Bargh (eds), The Psychology of Action: Linking Cognition and Motivation to Behavior (The Guilford Press, New York, NY, US), pp. 7-26.

Ryff, C.D. and C.L.M. Keyes: 1995, 'The structure of psychological well-being revisited', Journal of Personality and Social Psychology 69, pp. 719-727.

Shweder, R.A. and M.A. Sullivan: 1993, 'Cultural psychology: Who needs it?', Annual Review of Psychology 44, pp. 497-523. 
Suh, E.M.: 2002, 'Culture, identity consistency, and subjective well-being', Journal of Personality and Social Psychology 83, pp. 1378-1391.

Suh, E.M., E. Diener, S. Oishi and H.C. Triandis: 1998, 'The shifting basis of life satisfaction judgments across cultures: Emotions versus norms', Journal of Personality and Social Psychology 74(2), pp. 482-493.

Taylor, S.E. and J.D. Brown: 1988, 'Illusion and well-being: A social psychological perspective on mental health', Psychological Bulletin 103, pp. 193-210.

Uchida, Y., S. Kitayama, B. Mesquita and J.A. Rayes: 2001, Interpersonal sources of happiness: The relative significance in three cultures. Paper presented at 13th annual convention of the American Psychological Society, Toronto, Canada.

Veenhoven, R.: 1991, 'Is happiness relative?' Social Indicators Research 24, pp. $1-34$

Weber, M.: 1930, The Protestant Ethic and the Spirit of Capitalism. Translated by Talcott Parsons (Routledge. New York, NY).

Weisz, J.R., F.M. Rothbaum and T.C. Blackburn: 1984, 'Standing out and standing in: The psychology of control in America and Japan', American Psychologist 39, pp. 955-969.

Address for Correspondence:

YUKIKO UCHIDA

Graduate School of Human and Environmental Studies

Kyoto University

Sakyo-ku, Kyoto 606-8501

Japan

E-mail:yuchida@umich.edu

VINAI NORASAKKUNKIT

Minnesota State University - Mankato

SHINOBU KITAYAMA

University of Michigan 